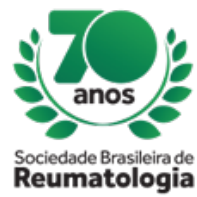

\title{
EOSINOPHILIC GASTROENTERITIS IN A PATIENT WITH SYSTEMIC LUPUS ERYTHEMATOSUS
}

Claudia Valeria Vierhout (Hospital PUC Campinas, Campinas, SP, Brasil), Nadia Regina Bossolan Schincariol (Hospital PUC Campinas, Campinas, SP, Brasil), José Alexandre Mendonça (Hospital PUC Campinas, Campinas, SP, Brasil), Lucas Eduardo Pedri (Hospital PUC Campinas, Campinas, SP, Brasil), Andre Marun Lyrio (Hospital PUC Campinas, Campinas, SP, Brasil), Rubens Bonfiglioli (Hospital PUC Campinas, Campinas, SP, Brasil), José Roberto Provenza (Hospital PUC Campinas, Campinas, SP, Brasil), Vanessa Ramos Guissa (Hospital PUC Campinas, Campinas, SP, Brasil), Fernanda Bertucci Sanches (Hospital PUC Campinas, Campinas, SP, Brasil), Thais Campos Ferreira Pinto (Hospital PUC Campinas, Campinas, SP, Brasil), Igor Tadeu Garcia Ferreira (Hospital PUC Campinas, Campinas, SP, Brasil), Marcello Imbrizi Rabello (Hospital PUC Campinas, Campinas, SP, Brasil)

\section{BACKGROUND}

Eosinophilic gastroenteritis (EGE) is a rare digestive disorder characterized by eosinophilic infiltration of gastrointestinal tract segments (in the absence of known causes for eosinophilia) and peripheral eosinophilia. Nonspecific symptoms may be shown, that is why the first step in diagnosing is suspecting EGE. Dysphagia, heartburn, abdominal pain, bloating, diarrhea, vomiting, melena, iron-deficiency anemia, malabsorption, protein-losing enteropathy may be related. The specific symptoms depend on the intestinal segment involved. Endoscopy and biopsy play a key role in diagnosis. Literature describes several gastrointestinal events associated with systemic lupus erythematosus (SLE), such as vasculitis and enteritis. However, there are only a few reports about the association of SLE and EGE. Due to its rarity, the follwing report is about a middle-age woman who developd a imune-related disease during remission of SLE.

\section{CASE REPORT}

A 54-year-old woman in treatment for systemic lupus erythematosus (diagnosed 12 years ago), in use of cloroquine, presented abdominal pain, vomiting and chronic diarrhea. Not found any remarkable signs in her physical examination. In fact, physical e laboratorial examns indicated SLE in remission (SLEDAI <3). There was no history of allergies. Laboratory tests revealed eosinophilia (eosinophil: 33\%). Erythrocyte sedimentation rate (ESR) and C-reactive protein (CRP) presented at normal levels. Patient recived treatment for verminosis, but the symptoms remaind. Endoscopic examination was performed, showing severe gastritis. The gastric biopsy was reported as eosinophilic gastroenterites - eosinophilics infiltration in the gastric pylorus and fundus. There were remission of symptoms with administration of prednisone in high doses $(0,5 \mathrm{mg} / \mathrm{kg})$.

\section{CONCLUSION}

The diagnosis of GE, by itself, is already a challenge due to its rarity and non-specific features. When associated with auto-imune diseases, some confounding factores can make this task even harder, once gastrointestinal symptoms can be related to activitie of the underlying disease, as well as to side effects of the drugs used in treatment. In some cases, immunosuppresive drugs may mask the symptoms and postpone the diagnosis. Once more, we emphasyze that the first step in diagnosing is suspecting EGE (especially in patients presenting abdominal pain and eosinophilia). 